\title{
Comparative Studies of Some Polypores Using High Performance Liquid Chromatography
}

\author{
Ofodile L. N., Attah L. E. Agbaje Williams and Simmonds, M. S. J
}

\begin{abstract}
Isolates of four polypores; Ganoderma colossum, Ganoderma lucidum, Trametes cingulata and Daedalea quercina were compared using the High performance liquid chromatographic profiles of their triterpenoids. A higher abundance of colossolactone E was found in Ganoderma colossum isolate (FC 876) when compared with FC 872 obtained at different periods and dried differently and 23hydroxycolossolactone E found in FC 876 was not observed in FC 872. Equal abundance of constituents was also found in Ganoderma lucidum isolates (FC 871 and FC 875) collected from different hosts and geographical locations. The isolates of Trametes cingulata that were of different ages showed predominance of the major constituents in FC 873 and FC 885 isolates when compared with FC 870. The abundance of the triterpenoid in the isolates of Daedalea quercina was almost doubled in FC 882 when compared with that of FC 878. These conform with the chemical spot test results on these polypores in a previous work. The ability of the polypores to produce triterpenoids is affected by their age, period of collection, geographical location and method of drying, which also affected the High Performance Liquid Chromatography characteristics of their secondary metabolites.
\end{abstract}

Keywords: High Performance Liquid Chromatography, Polypore, triterpenoids, comparative study

\section{Introduction}

Polypores are aphyllophorales with corky, woody, leathery, and papery basidiocarps (Zjawiony, 2004). Aphyllophorales are mushrooms in the class basidiomycetes with holobasidia but usually lack gills (Kirk et al., 2001), they include Ganoderma species, Tremetes species, Daedalea species and other basidiomycetes. Polypores cause diseases such as basal stem rot of oil palm in South East Asia caused by Ganoderma boninense, Ganoderma Butt Rot of Palms by Ganoderma zonatum and red rot of Acacia trees caused by G. philippii. Polypores also cause wood rot of timber and are of great economic importance in ornamentals and forest trees in the tropics and temperate parts of the world (Smith and Sivasthamparam, 2003). Medicinal basidiomycetes represent unlimited source of phytochemical such as primary and secondary metabolites (Roja and Rao, 1998). Medicinal importance of Ganoderma has been well researched and confirmed in Asia (Zjawiony, 2004), and Ganoderma lucidum, G. colossum, G. boninense, G. resinaceum, Trametes cingulata, T. mariana, and Daedalea quercina from Nigeria have also been reported to be active against Bacillus subtilis and Pseudomonas syringae which were plant pathogens (Ofodile et al., 2005; Ofodile, 2006). Morphological and several chemical tests are traditionally employed as criteria in the characterization of polypores (Ryvarden and Johansen, 1980; De Rosa, 2003). Although, Ganoderma has immense medicinal values as reported by different authors (Shiao et al., 1999; Smania et al., 1999; 2001; Zjawiony, 2004), the taxonomy of the genus is in chaos (Smith and Sivasthamparam, 2003).

The conventional method of characterization of polypores, which are the morphological taxonomic techniques, have been found to be insufficient where morphological controversies arise as in some polypores like Ganoderma species (Smith and Sivasthamparam, 2003), thus the need for a simple alternative method for the 
identification of the polypores. According to Su et al, (2001) in their work on the use of High performance Liquid chromatographic analysis (HPLC) of triterpenoids for the identification of species of Ganoderma from a large number of isolates collected from Taiwan, HPLC is a single easy way to differentiate among species of the genus Ganoderma.

This paper reports the comparison of the triterpenoids profiles of Ganoderma colossum, Ganoderma lucidum, Trametes cingulata and Daedalea quercina with reference to their age, habitat, period and localities using HPLC.

\section{Materials and method \\ Polypore materials}

Isolates of the basidiocarps of species of polypores were collected from different parts of Southern Nigeria. Two isolates of Ganoderma lucidum (cf) (Curtis) P. Karst were collected from the stump of Persia americana (FC 875) and Eliaes guineensis (FC 871) in Yaba College of Technology, Lagos and Obosi, Anambra State respectively. An isolate of G. colossum (Fr) C. F. Baker was obtained from dead logs of Delonix regia Raf (FC 876) and another isolate from dead logs of Acacia species (FC 872), Yaba College of Technology and three isolates of Trametes cingulata Berk (FC 870, FC 873 and FC 885) of different ages (young, mature and old specimens) were isolated from the dead log of Eliaes guineensis and two isolates of Daedalea quercina (FC 878 and FC 882) which were the mature and young specimens respectively were collected from dead logs of Mangifera indica, Obosi, Anambra State. After collection the polypores were number with fungi collections numbers (FC) for easy reference. The polypores were then identified by their corky, woody and leathery basidiocarps and other characteristics (Ryvarden and Johansen, 1980; Kirk et al., 2001). Voucher specimens were deposited in the Herbarium of Royal Botanic Garden, Kew, UK.

Preparation of polypore materials

Ganoderma colossum (FC 872) was oven dried, while FC 876 was air dried at room temperature. Isolates of Daedalea quercina, Ganoderma lucidum and Tremetes cingulata isolates were also air dried at room temperature. Dried ground material $(2 \mathrm{~g})$ of each isolate of Ganoderma colossum and 0.2 grams of Daedalea quercina were soaked overnight in $40 \mathrm{ml}$ of hexane: dichloromethane (2:7). One gram of each isolate of Ganoderma lucidum and Trametes cingulata were soaked overnight in $40 \mathrm{ml}$ of $100 \%$ methanol in a conical flask and filtered using No 1 Whatman filter paper. Both extracts were allowed to evaporate under room temperature in the fume cupboard and were redissolved in $100 \%$ methanol $(1 \mathrm{mg} / \mathrm{ml})$.

\section{High Performance Liquid Chromatography (HPLC)}

Analytical HPLC with diode array detection (HPLC-DAD) was used in analyzing the samples. The HPLC system consisted of water LC 600 pump and 996 photodiode array detectors Merck Lichrospher 100RP-18 $(5 \mu \mathrm{m})$ with $4.0 \mathrm{~mm}$ (i.d.) $\times 250 \mathrm{~mm}$ column were used. Gradient profiles based on two solvents, denoted A and B, were employed. A was $2 \%$ aqueous acetic acid ( $\mathrm{HOAc}$ ) and $\mathrm{B}$ was methanol $(\mathrm{MeOH})$. The ratio of combination of methanol, acetic acid and water $\left(\mathrm{MeOH}-\mathrm{HOAc}-\mathrm{H}_{2} \mathrm{O}\right)$ is 18:1:1. Initial conditions were $75 \% \mathrm{~A}, 25 \%$ with a linear gradient reaching $\mathrm{B}=100 \%$ at $\mathrm{t}$ $=20 \mathrm{~min}$. This was followed by isocratic elution $(\mathrm{B}=100 \%)$ to $\mathrm{t}=25 \mathrm{~min}$, after which the programme returned to the initial solvent composition. Column temperature was 
maintained at $30^{\circ} \mathrm{C}$; a flow rate of $1.0 \mathrm{ml}$ was made by autosampler. HPLC profiles of all the samples were read at wavelength of $335 \mathrm{~nm}$. The injection volume of $40 \mu \mathrm{l}$ was used for the isolates of $G$. colossum and $20 \mu \mathrm{l}$ for the other samples. The peaks and retention times of the isolates of the different species of polypore were then compared.

\section{Results and discussion}

HPLC profiles of Ganoderma colossum (FC 872 and FC 876), G. lucidum (FC 871 and FC 875), Trametes cingulata (FC870, FC 873, and FC 885) and Daedalea quercina (FC 878 and FC 882) are shown in Figures 1- 4. The peaks were assigned numbers for easy interpretations, which represent different triterpenoids in each genus and species treated.

Ganoderma colossum (FC 872 and FC 876)

The HPLC profiles (Fig. 1A) of isolates of G. colossum (FC 876) showed four well resolved peaks with retention times varying from $19.930-26.230 \mathrm{~min}$. while in other isolates (FC 872), only three distinctive peaks were observed at similar retention times (Fig. 1B). The peaks of the secondary metabolites were abundantly distributed in the basidiocarps of the fungi isolates. Peaks 5 and 6 were the major constituents obtained in both isolates (FC 872 and FC 876). However, G. colossum (FC 876) also contained three other peaks (peaks 1, 2 and 3) which were not shown in FC 872, while in FC 872 a major constituent peak (Peak 4) which was restricted to FC 872 and other isolate FC 876 did not show any peak. The intensities of peaks 5 and 6 found were stronger in FC 876 than in FC 872 indicating more abundance of colossolactone E (Peak 5) in FC 876 than FC 872.

FC 876 also contained high amount of a constituent, 23-hydroxycolossolactone E, observed as peak 1 which was absent in FC 872 (Table 1). The absence of peaks 1, 2, 3 in FC 872 may be due to the fact that FC 872 was an older specimen to FC 876 and was collected from a different habitat and could have undergone certain chemical changes during the period. According to Muller-Riebue et al, 1997; Bankova et al, 1998; Riipi et $a l$, (2002), the distribution of these compounds can depend on the physiological condition of the plant which vary during the year.

Table 1: HPLC characteristics of Ganoderma colossum

\begin{tabular}{|l|l|l|l|}
\hline Polypore isolates & Peak number & Retention Time (min. & Peak Intensity \\
\hline \multirow{3}{*}{ FC 872} & 5 & 24.586 & 0.37 \\
& 6 & 26.250 & 0.16 \\
& 4 & 23.015 & 0.32 \\
\hline \multirow{3}{*}{ FC 876 } & 5 & 24.540 & 1.85 \\
& 6 & 26.230 & 0.30 \\
& 3 & 22.970 & 0.35 \\
& 2 & 21.427 & 0.01 \\
& 1 & 19.930 & 0.70 \\
\hline
\end{tabular}




\section{Ganoderma lucidum (FC 871 and FC 875)}

HPLC profiles of G. lucidum showed clustered peaks with retention times ranging from 5.889-19.164 minutes are presented in Fig. 2A and 2B. In Figure 2A (FC 871), the maximum and minimum intensities of the major constituents were observed at retention times 5.889 and 17.497 min respectively, while in Fig. 2B (FC875) the major constituents had maximum and minimum intensities at retention times 6.370 and $18.585 \mathrm{~min}$. respectively. The chemical constituents of G. lucidum isolates (FC 871 and FC 875) were very similar as shown by their relative retention times and intensities (Table 2). Majority of the peaks (peaks $6,7,8,9$ ) were distributed in the two isolates, suggesting that these could be the same compounds. Also, the major components of the two isolate (peak 8) have relatively close intensities of 0.06 in (FC 871) and (FC 875) suggesting equal abundance of the constituents in both isolates. The close similarities found in the chemical components of the isolates of G. lucidum collected from different hosts is an indication that secondary metabolites are restricted in their distribution and often in characteristics in of individual species (Campell, 1984, Larsen, 1998), whereas, the variations they showed could be because they were collected from different geographical regions of Southern Nigeria. Su et al, (2001) also reported the differences between $G$. lucidum and G. tsugae samples from three different regions of Taipei, Taiwan using HPLC analysis of their triterpenoids.

Table 2: HPLC characteristics of Ganoderma lucidum

\begin{tabular}{|l|l|l|l|}
\hline Polypore isolates & Peak number & Retention Time (min.) & Peak Intensity \\
\hline \multirow{3}{*}{ FC 871 } & 1 & 5.889 & \\
& 3 & 11.163 & 0.019 \\
& 6 & 13.576 & 0.010 \\
& 7 & 15.339 & 0.024 \\
& 8 & 17.487 & 0.030 \\
& 9 & 18.523 & 0.060 \\
& 11 & 19.164 & 0.036 \\
& 2 & 6.370 & 0.034 \\
\hline & 6 & 13.589 & 0.018 \\
& 675 & 15.345 & 0.038 \\
& 7 & 17.452 & 0.038 \\
& 8 & 18.585 & 0.055 \\
& 9 & 19.132 & 0.070 \\
& 10 & & 0.060 \\
\hline
\end{tabular}




\section{Trametes cingulata (FC870, FC 873, and FC 885)}

Figure 3A (FC870), 3B (FC 873) and 3C (FC 885) show the HPLC profiles of $T$. cingulata isolates. Peaks 1, 14, and 15 were commonly distributed among the three isolates, while peak 2 was found in FC 870 and FC 873. As shown in Table 3, the intensity of peak 2 is stronger in FC 870 than FC 873. Peak 13 was also found in both FC 873 and FC 885 but the intensity is slightly stronger in FC 885 than in FC 873. Peak 14 had the strongest intensity in FC 873, and was relatively strong in FC 885 with the weakest intensity of 0.001 recorded in FC 870. The intensities of peak $14(0.015$ and 0.010 ) in both FC 873 and FC 885 respectively indicated that the abundance of their triterpenoids similar. The constituents of $T$. cingulata (FC 873) were found to be more chemically related to the other isolates (FC 870 and FC 885). The major constituent of FC 870 was peak 2 with intensity of 0.030 , while in FC 873; it showed a rather weak intensity of 0.006 (Table 3). However, this constituent of FC 870 (Peak 2) was not found in FC 885 which suggests that the young specimen of isolates of T. cingulata (FC 885) did not contain this metabolite that was in the mature and old specimens which could be attributed to the sythesis of certain chemical substance by the fungus at the early stages of development, which were produced afterwards at the advanced stages. Smith, (1976) reported that the changes in the flavonoid content in peas were rapid enough to be causally related to growth changes.

Table 3: HPLC characteristics of Trametes cingulata

\begin{tabular}{|l|l|l|l|}
\hline Polypore isolates & Peak number & Retention Time (min.) & Peak Intensity \\
\hline FC 870 & 2 & 7.999 & 0.030 \\
& 7 & 15.258 & 0.006 \\
& 14 & 24.585 & 0.001 \\
& 15 & 26.462 & 0.001 \\
\hline & 1 & 5.840 & 0.005 \\
FC 873 & 2 & 7.989 & 0.006 \\
& 4 & 13.966 & 0.010 \\
& 13 & 23.071 & 0.004 \\
& 14 & 24.576 & 0.015 \\
& 15 & 26.456 & 0.010 \\
\hline FC 885 & 1 & 26.254 & 0.007 \\
& 13 & 24.585 & 0.010 \\
& 14 & 23.077 & 0.005 \\
& 15 & 5.863 & 0.001 \\
\hline
\end{tabular}




\section{Daedalea quercina (FC 878, and FC 882)}

The HPLC profiles of Daedalea quercina isolates are presented in Fig 4A (FC 878 ) and Fig. 4B (FC 882). Two distinctive peaks (9 and 10) were found in FC 878, at retention times 24.588 and 26.261 min respectively. In Fig. 4B (FC 882), nine peaks numbered $1,2,4,5,6,7,8,9,10$ were identified at retention times ranging from 11.863 26.259 min (Table 4). The major constituents in both isolates were identified as peaks 9 and 10. The intensity of peak 10 was the same in both isolates but peak 9 was slightly more intensive in FC 882 than FC 878. This suggests that the abundance of the triterpenoid in FC 882 was almost double that of FC 878. However, peaks 1, 2, 4, 5, 6, 7 and 8 , which were found in FC 882, were absent in the FC 878 isolates. D. quercina (FC 882 ) was also a young isolate that contained more constituents than the mature specimen, which also implicated developmental growth effect.

Table 4: HPLC characteristics of Daedalea quercina

\begin{tabular}{|l|l|l|l|}
\hline Polypore isolates & Peak number & Retention Time (min.) & Peak Intensity \\
\hline FC 878 & & & \\
& 9 & 24.588 & 0.010 \\
& 10 & 26.261 & 0.008 \\
\hline \multirow{3}{*}{ FC 882 } & 2 & 12.754 & 0.018 \\
& 6 & 20.080 & 0.007 \\
& 9 & 24.589 & 0.018 \\
& 10 & 26.259 & 0.008 \\
\hline
\end{tabular}

The chemical analysis of some polypores from Nigeria showed that in the chemical spot tests on the isolate of $T$. cingulata and D. quercina (FC 882) the two contained phenolic substances and retained the colour of Melzer's reagent Ofodile (2006). The mature tissues of $T$. cingulata and D. quercina (FC 882) turned light brown in potassium hydroxide $(\mathrm{KOH})$ and ammonium hydroxide $\left(\mathrm{NH}_{4} \mathrm{OH}\right)$ and brown in ferrous sulphate $\left(\mathrm{Fe}_{2} \mathrm{SO}_{4}\right)$ solutions but the young specimen did not react with these reagents, whereas, the other polypores reacted in the same manner with same reagents (Ofodile, 2006). The varied chemical constituents in the isolates of D. quercina were possibly the reason for different reactions shown with the reagents.

\section{Conclusion}

Unique peaks were observed in G. colossum, G. lucidum, and T. cingulata and D. quercina, which represent the potential value of that particular species. I addition, present study reveals the influence of age, locality, method of drying and season on the secondary metabolites isolation and characterization. 


\section{References}

Bankova, V. Boudourova-Krasteva, G., Popov, S., Sforcin, J.M, and Funari, S.R.C. (1998) Seasonal variation of the chemical composition of Brazilian propolis, Apidologie 29 (4): 361-367.

Campell, I.M. (1984) Secondary metabolism and microbial secondary metabolism. cells" Anticancer Research 13(3): 671-5.

De Rosa, J. (2003) The mushroom place, Mycophile 1-6pp.

Kirk, P.M., Cannon, P.F., David, J.C and Stalpers, J.A. (2001): Ainsworth and Bisby's

Dictionary of the fungi (9th ed.), CAB, Bioscience, UK, 655pp.

Larsen, T.O. and Frisvad, J.C. (1995) Comparison of different methods for collection of volatile chemicals marker from fungi. J. Microbial methods 24: 135-144.

Muller-Riebeu, F.J., Berger, B.M., Yegen, O., and Cakir, C. (1997) Seasonal variation in the chemical compositions of essential oils of the selected aromatic plants growing wild in turkey. Journal of agriculture and Food chemistry 45(12): 4821-4825

Ofodile, L. N. (2006) Taxonomy and Antimicrobial activity of some basidiomycetous fungi in Southern Nigeria. PhD Thesis, Department of Botany and Microbiology, University of Lagos, Akoka, Lagos, Nigeria. 252pp.

Riipi, M., Ossipov, V., Lempa, K., Haukioja, E., Koricheva, J., Ossipova, S., and Pihlaja, K. (2002) Seasonal changes in birch leaf chemistry: are there trade off between leaf growth and accumulation of phenolics. Oecologia 130(3): 380-313pp.

Roja, G. and Rao, P. S. (1998) Biotechnology investigation in medicinal plants for the product ion of secondary metabolites In: Role of Biotechnology in medicinal and Aromatic plants vol 1, (Irfan A., A. and Atiya, K. editors) Hong Kong, 201pp.

Ryvarden, L. and Johansen, I. (1980) A preliminary polypore flora of east Africa.

Fungiflora: Oslo, Norway, 636pp.

Shiao, M.S, Lee, R.R., Lin, L. J., and Wang, C.T. (1999) Natural fungus Ganoderma

lucidum. In: Food phytochemistry for cancer prevention 11: tea, spices and herbs.

(HOCT. Editor) p335-342, Washington DC:American Chemical Society.

Smania, A. Modache, D.F., Smania, E.F. and Cuneo, R.S. (1999) Antibacterial activity of steroidal compounds from Ganoderma applanatum (Pers) Pat. (Aphyllophoromycetideae) fruitbody. Int. J. Med. Mushr. 1:325-330.

Smania, A. Monache, F.D., Loguericio-Leite, C., Smania, E.F.A., and Geber, A.L (2001) Antimicrobial activity of basidiomycetes. International Journal of Medical Mushrooms 3:87.

Smith, B. J, and Sivathamparam, K. (2003) Morphological studies of Ganoderma

(Ganodermataceae) from the Australiasian and Pacific regions. Aus. System. Bot.

16:487 - 503 .

Su C-H., Hang Y-Z., Ho H-O., Hu C-H., Sheu M-T. (2001) High performance liquid chromatographic analysis for the characterization of triterpenoids from Ganoderma. Journal of chromatographic Science. 39, 3:93-100 (8).

Zjawiony J. K. (2004) Biologically active compounds from Aphyllophorales (polypore) fungi. Nat. Prod. 67: 300-310.

Zoberi, M. H, (1972) Tropical Macrofugi: Some common species. The Macmillan Press Ltd, London, 158pp. 

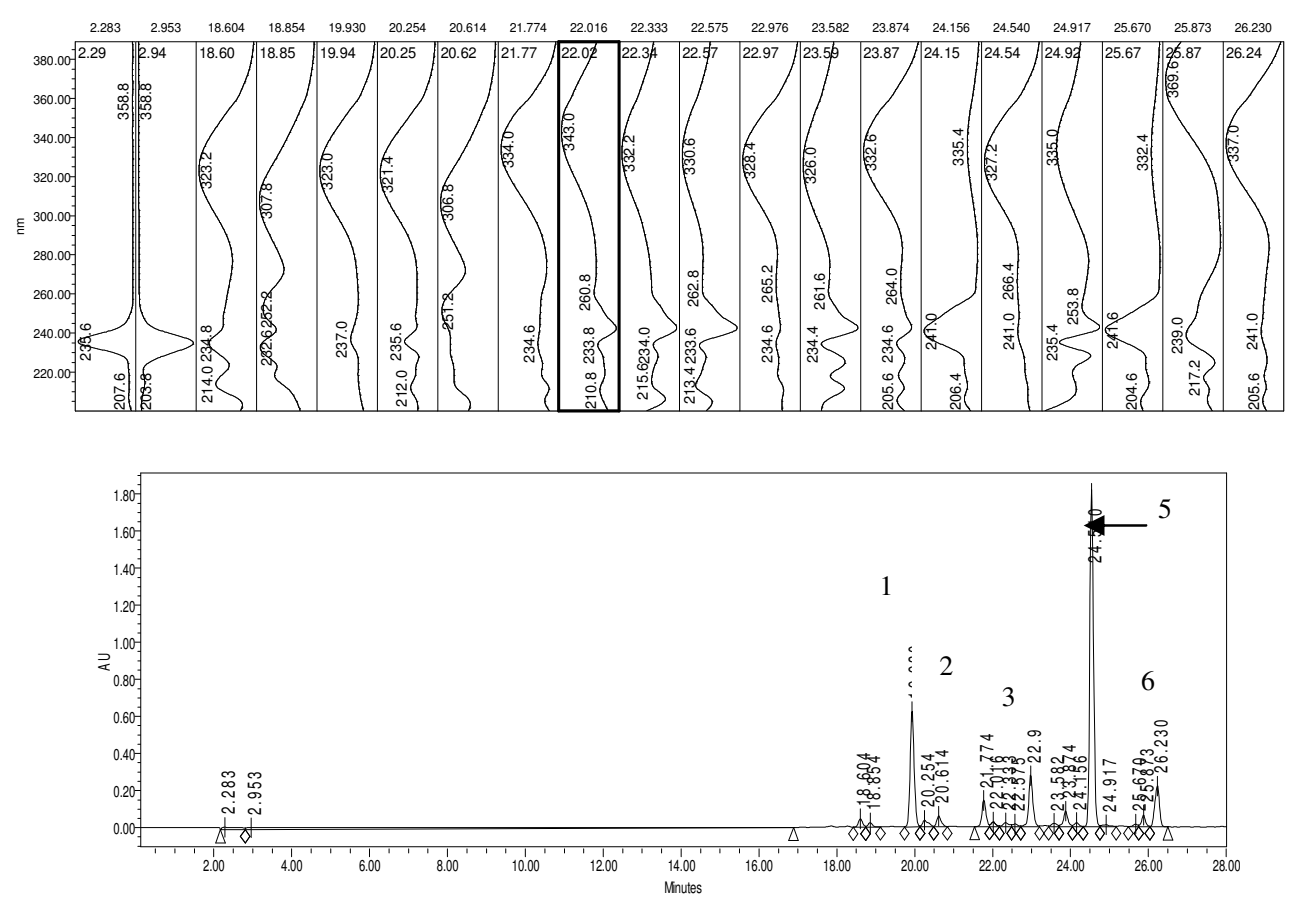

A
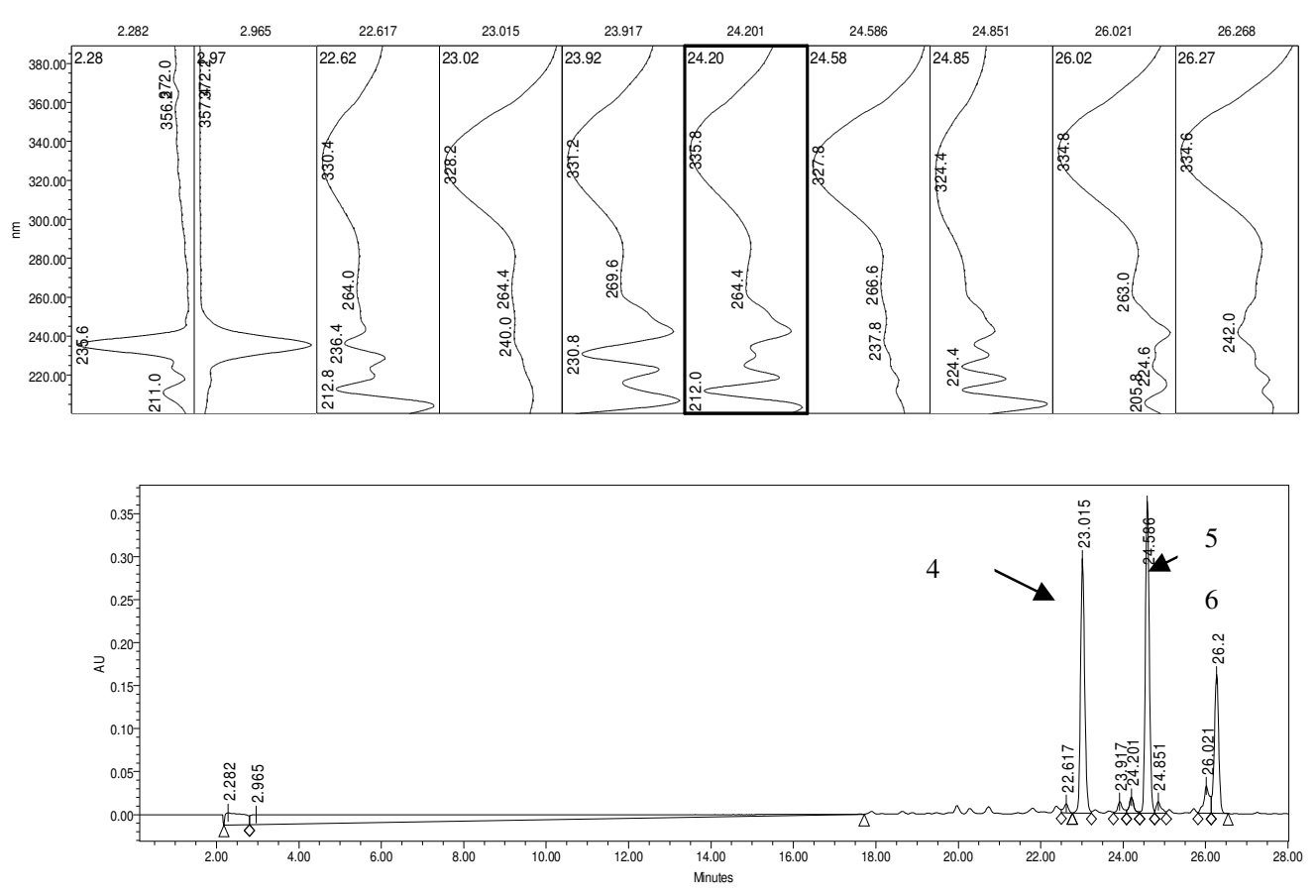

B

Figure 1: HPLC profiles of Ganoderma colossum (A, FC 876 and B, FC 872) 

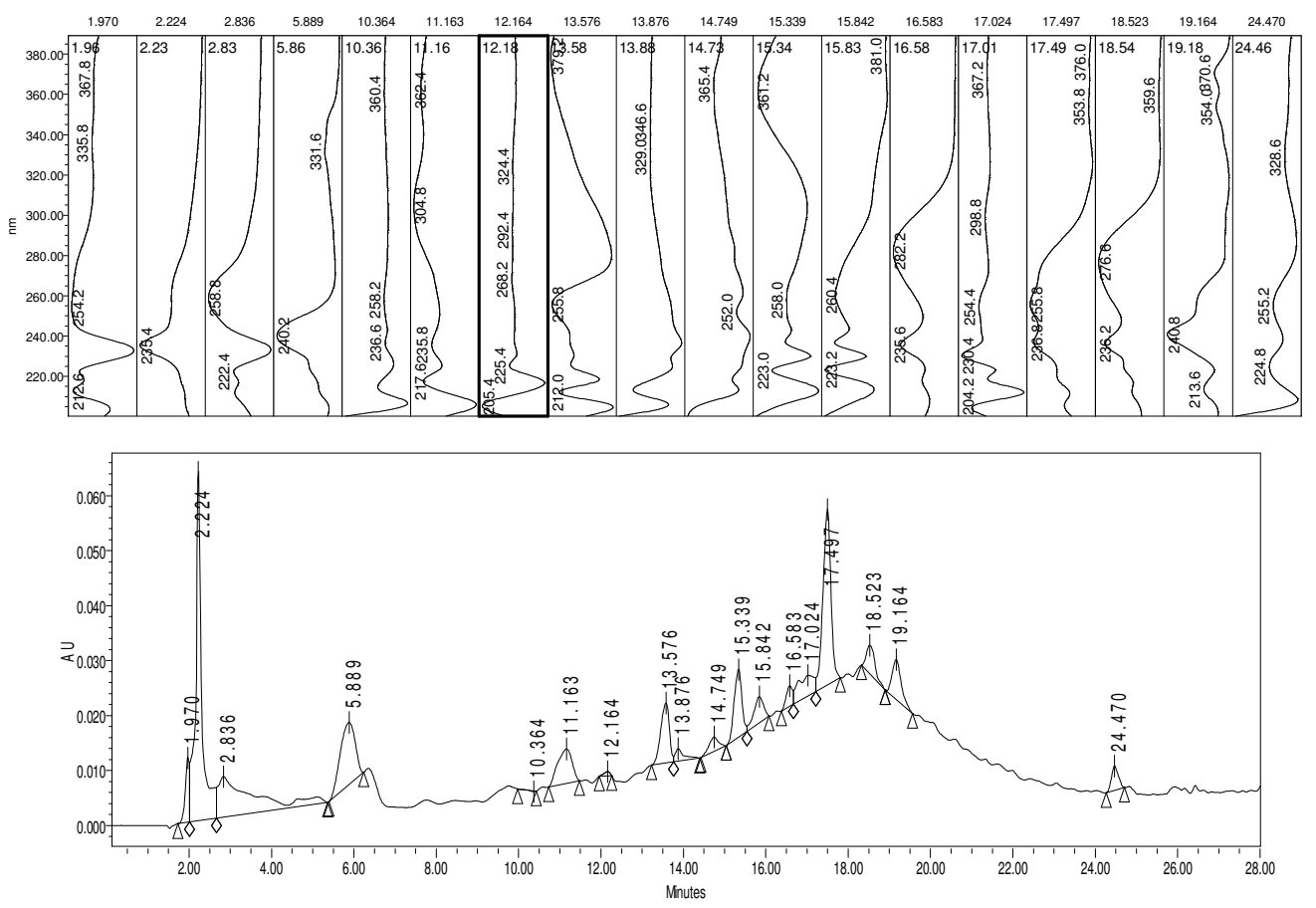

A
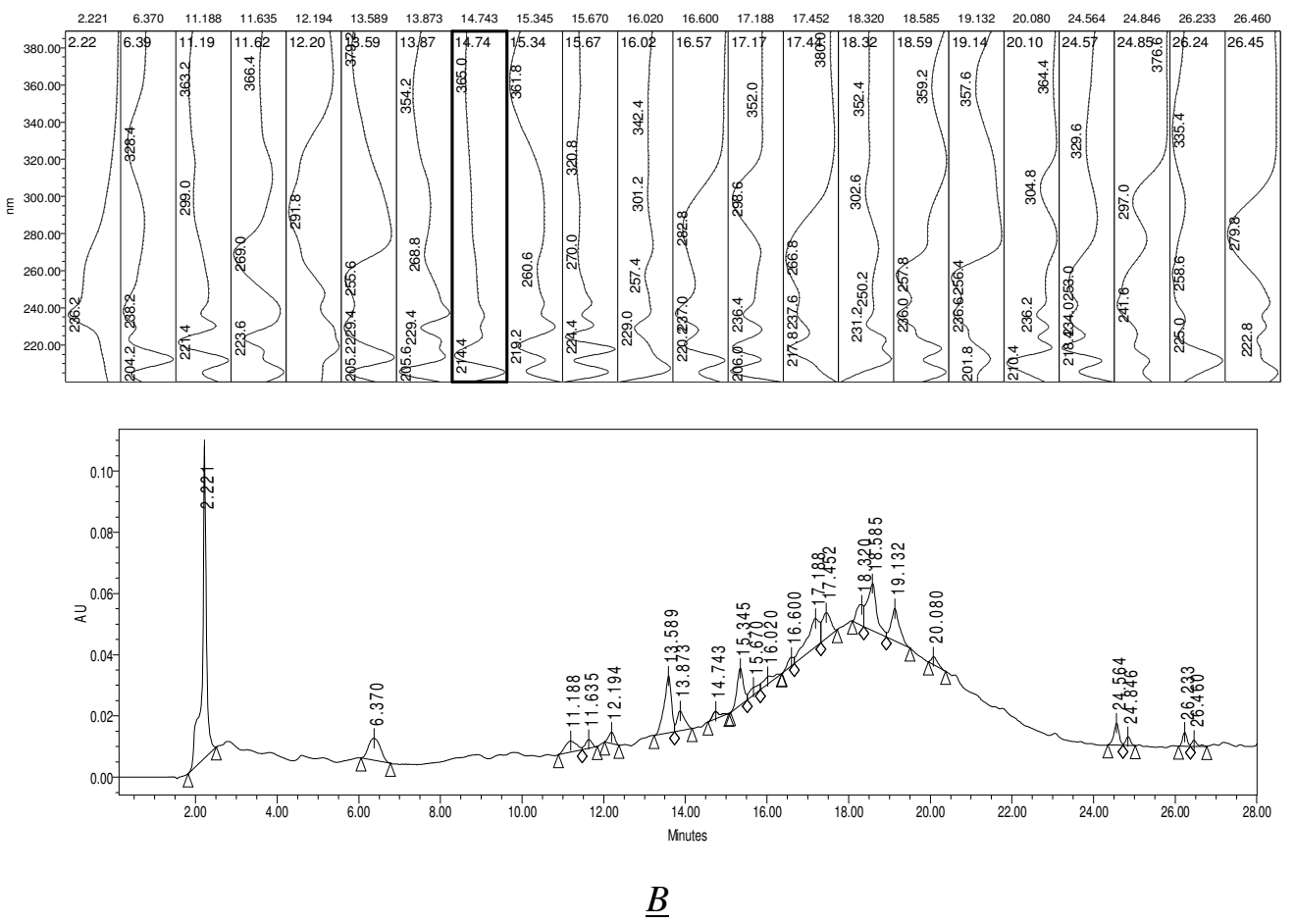

Figure 2: HPLC profiles of Ganoderma lucidum (A, FC 871 and B, FC 875) 

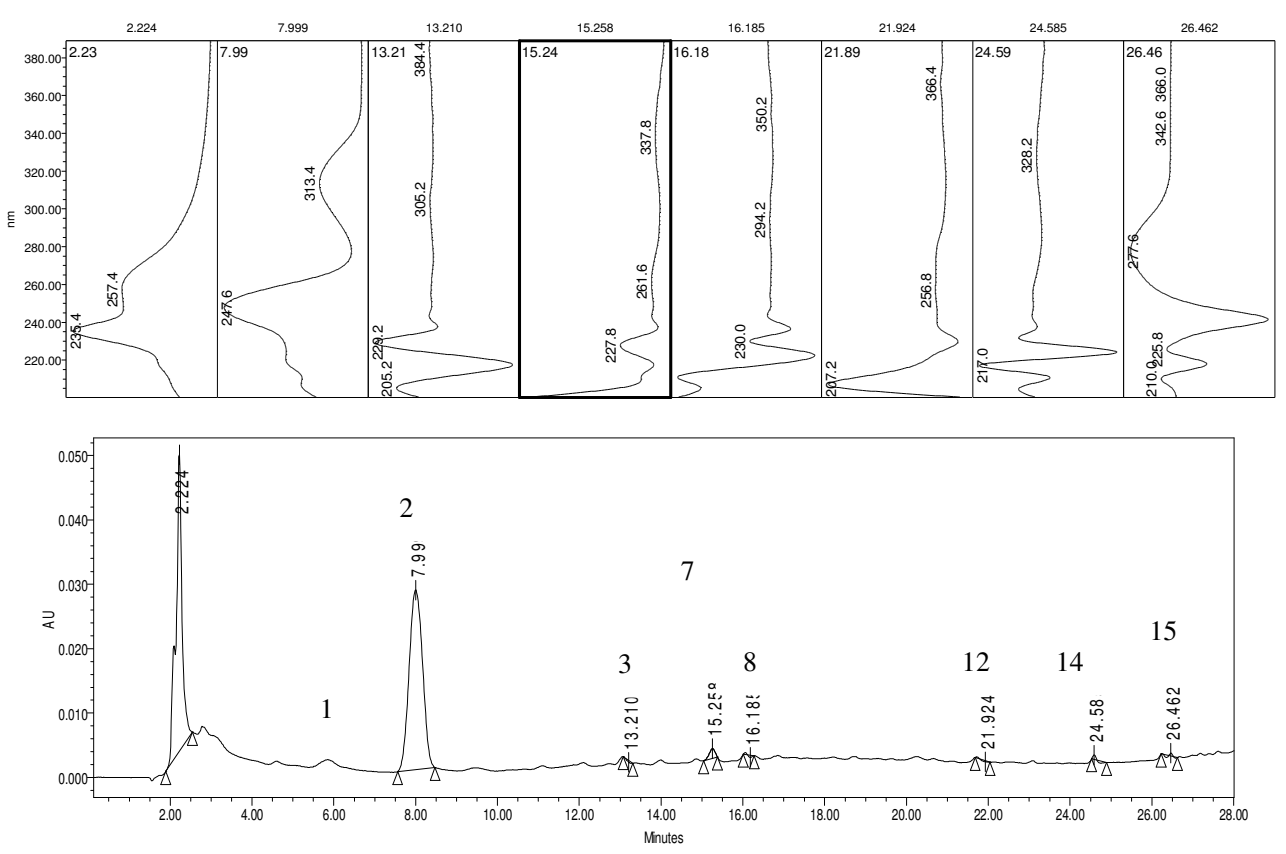

$\underline{A}$
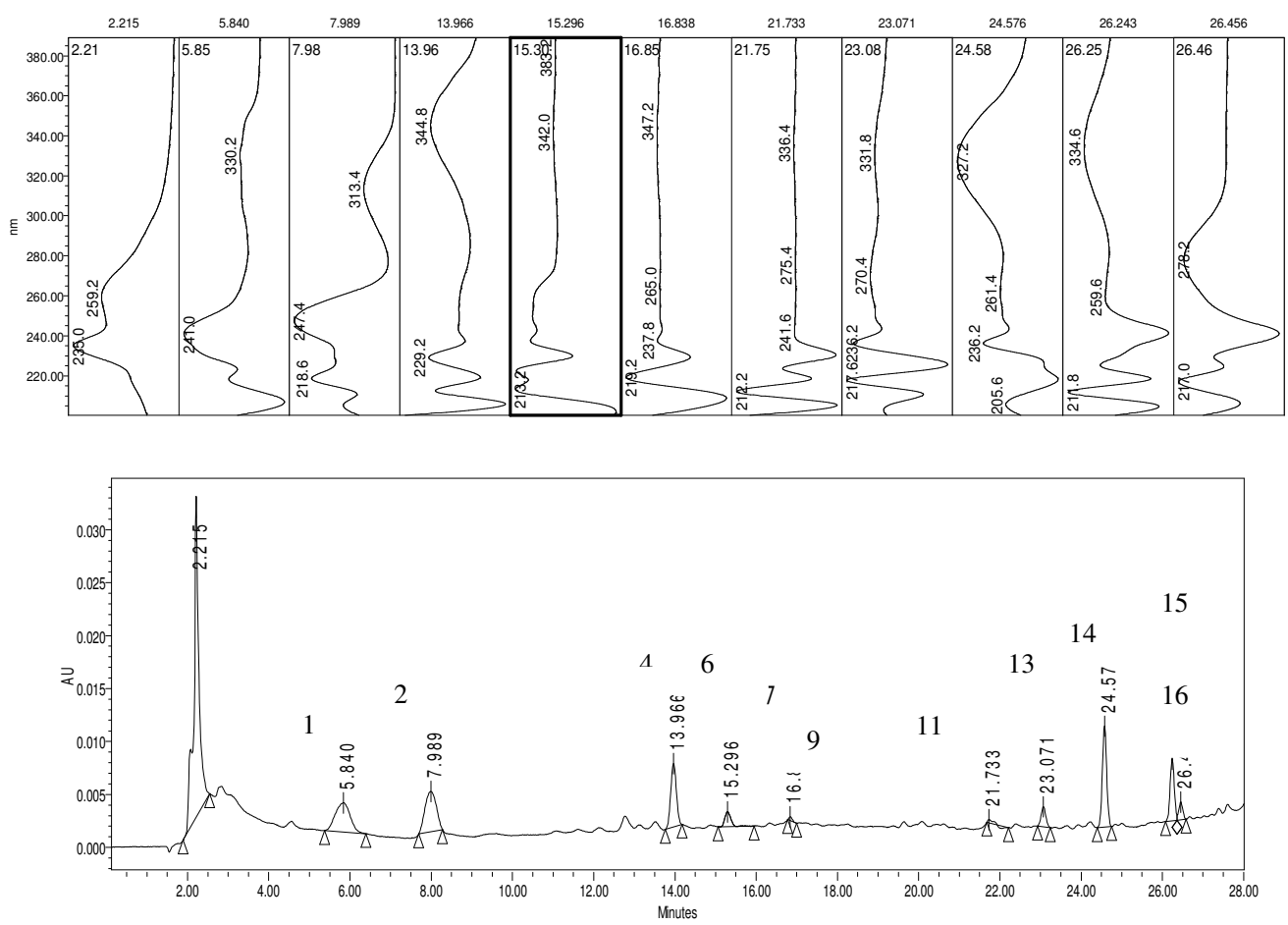


\section{$\underline{B}$}

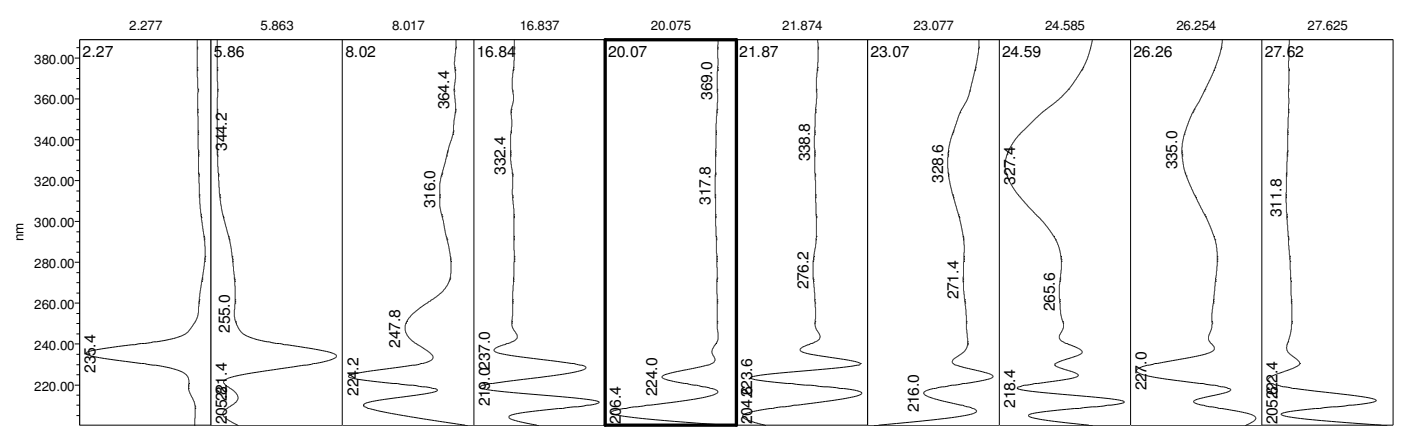

14

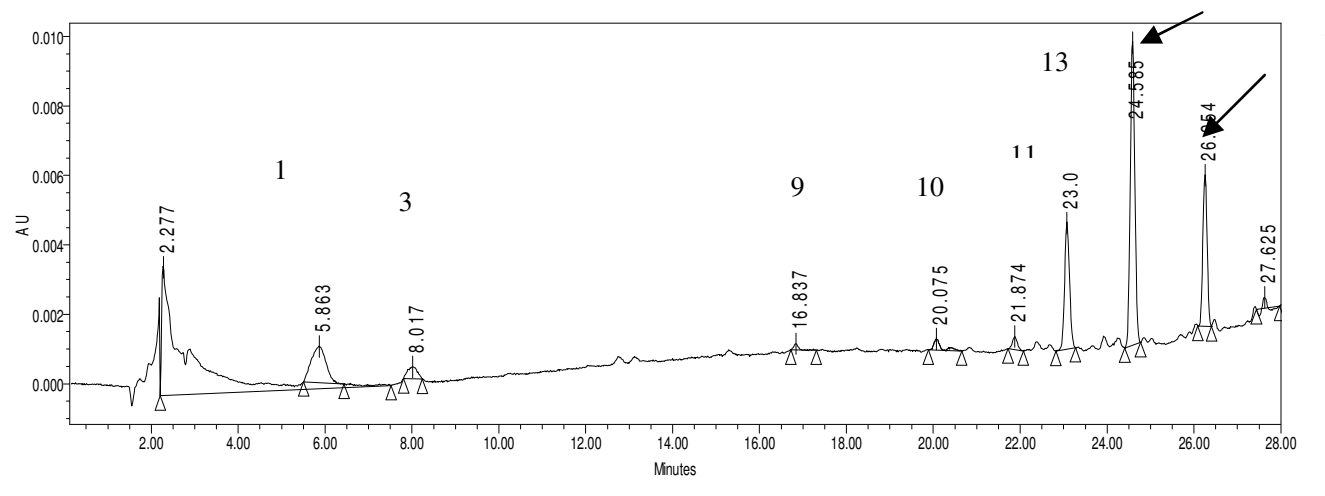

$\underline{C}$

Figure 3: HPLC profiles of Trametes cingulata (A, FC 870; B, FC 873 and C, FC885) 

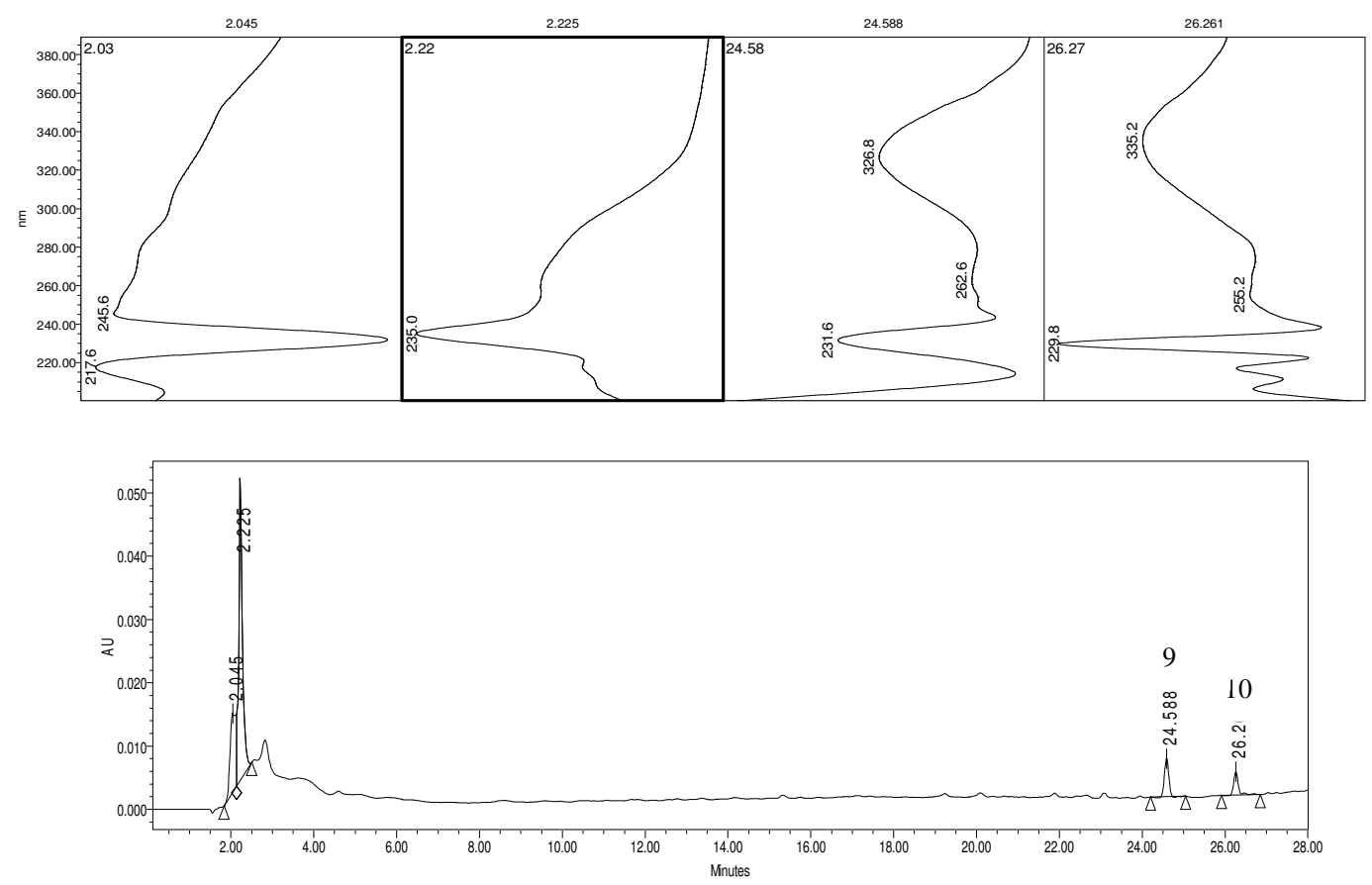

A
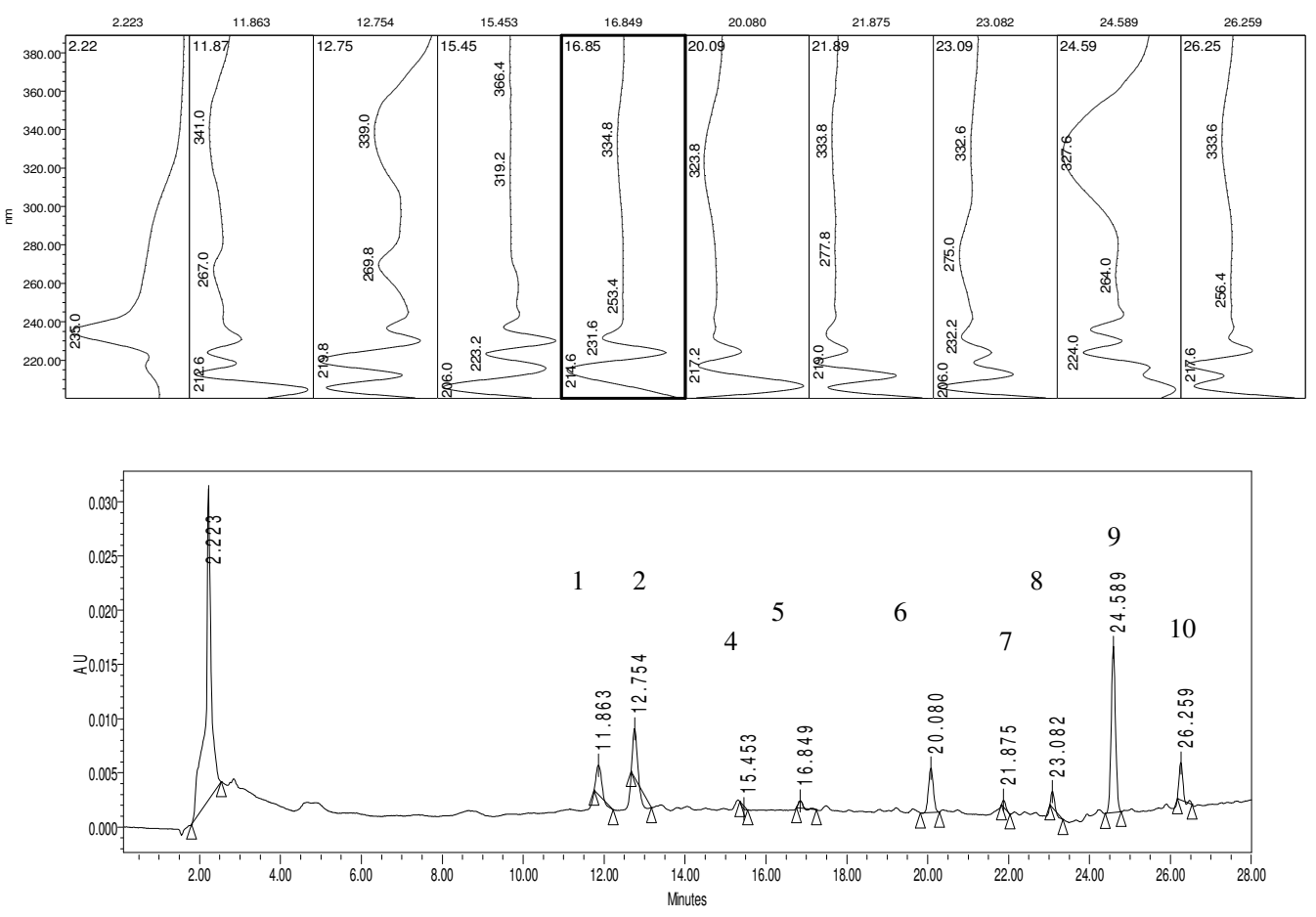

B

Figure 4: HPLC profiles of Daedalea quercina ( A, FC 878 and B, FC 882 